defectos menores de la cubierta del libro, los contenidos son de alta calidad.

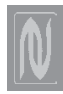

\section{Meditation and the Martial Arts}

Por Michael L. Raposa

Charlottesville, VA: University of Virginia

Press, 2003

192 páginas, $13,3 \times 20,3 \mathrm{~cm}$.

I.S.B.N.: 08-1392-238-0 • \$22.95

Disponible en:

The University of Virginia Press

Box 400318

Charlottesville, VA 22904-4318

Toll-free Tel: 800.831 .3406

Toll-free Fax: 877.288.6400

Email: vapress@virginia.edu

www.upress.virginia.edu

\section{Revisión por David O'Regan}

La obra de Raposa Meditation and the Martial Arts [La Meditación y las Artes Marciales] es un libro de dimensiones físicas modestas, aunque es grande en ambición y de riqueza en los contenidos. Raposa declara que su interés esta en "las artes marciales concebidas como practicas meditativas y en la meditación concebida como una disciplina marcial" (p. 2), y apoya sus impresionantes credenciales académicas con la experiencia práctica en las artes marciales. En su prólogo, el autor reivindica que sus habilidades en las artes marciales son "rudimentarias", pero confiesa su experiencia en una variedad de estilos, incluyendo el Aikido, Taijiquan, Iaido, y Tang Soo Do.

El estudio está dividido en cinco capítulos-los tres primeros ofrecen estudios de casos de los aspectos meditativos del Aikido; de las artes Taoístas de Taijiquan, Baguazhang, y Xingyiquan; y de ideas relacionadas con la tradición Hindu, Zen, e Islámica-. El cuarto capítulo trata del combate espiritual en la teología cristiana, y el quinto relaciona el tema de estudio con las escrituras de tres filósofos americanos -William James (18421910), Charles S. Pierce (1839-1914), y Josiah Royce (1855-1916) -.

Aunque los tres capítulos iniciales pueden parecer a primera vista meras repeticiones del conocimiento existente, el texto se yergue con nuevas percepciones sobre los temas objeto de discusión. De hecho, en casi todas las páginas del libro hay algo para estimular la mente. Para este crítico, los aspectos del análisis de Raposa más originales y que hacen reflexionar pueden encontrarse en las comparaciones entre las prácticas de meditación en las artes marciales asiáticas y la idea de guerra espiritual en el ascetismo cristiano. En particular, la espiritualidad marcial y los ejercicios meditativos de Ignacio de Loyola son un recuerdo de la universalidad del tema de la iluminación a través de las prácticas meditativas "combativas" y las disciplinas espirituales relacionadas (incluyendo el ritual y la oración).

Aunque el estudio de Raposa tiene mucho que elogiar, este crítico sostiene dos dudas. Primero, podría arquear las cejas ante las excesivas generalizaciones ocasionales del autor. Esto puede deberse al pequeño tamaño del libro, el cual limita el alcance para regresar a los principios de los temas mencionados de pasada. Tomando un ejemplo, muestra quizás una falta de crítica de la idea de las raíces históricas de Irán, a través del judaísmo helenístico, del gnosticismo (pp. 92-93). Esta idea de gnosticismo como originaria del Zoroastrismo tiene una sólida tradición intelectual entre los escolares orientalistas de los siglos XIX y XX de una rama "genealógica", pero ha sido discutida por los teólogos y los historiadores de la religión (como Karen L. King) quien pone en duda la idea misma del gnosticismo como un fenómeno histórico discontinuo. Nada de estos debates se recoge en la corta discusión del tema que realiza Raposa.

La segunda duda se refiere al aparente desconcierto en el tema central de este es- tudio, ya que se queda en la superficie al interpretar la comprensión del sentido de las experiencias de los practicantes orientados hacia el aspecto marcial meditativo. Leer el libro es como avanzar a tientas dentro de un pajar, sólo para encontrarlo en gran parte vacío en su esencia. $\mathrm{O}$, diciéndolo de otra manera, parece que las referencias basadas en libros, notas al pie de página, y la lógica magistral se disuelven en las extrañas sombras metafísicas proyectadas por las artes marciales meditativas. Esto podría sugerir al lector una limitación en la naturaleza de la empresa subyacente al libro de Raposa: el autor trae las herramientas del estudioso para analizar minuciosamente las áreas de experiencia que, discutiblemente, no son responsables de ser entendidas por el intelecto.

Si las experiencias de la actividad somática cargada espiritualmente son inexpresables en palabras -y el autor insinúa esto cuando declara en su prólogo que las comprensiones del Tao son "demasiado grandes para ser verbalizadas"- y si uno acepta que esta inexpresividad es intrínseca a la meta final del camino marcial meditativo, cualquier análisis intelectual necesariamente no llegará a su objetivo. El enfoque académico simplemente no puede extenderse por las artes marciales meditativas como una marea de espuma a través de las cavernas de la orilla y, retrocediendo, dejárlas desnudas y despojadas de misterio.

Sin embargo, reflejar estas dudas es evidenciar una tibia protesta. El intelecto debería ser tolerante con lo misterioso y debería buscarlo y no esconderlo o suprimirlo, antes al contrario, intentando vivir en paz con él en una relación de influencia mutua. Y Raposa ha conseguido esto en gran medida. Dentro de las limitaciones inherentes de un trabajo que intenta intelectualizar lo que sólo puede ser entendido más allá de los confines del intelecto, Raposa ha escrito el mejor y más accesible estudio académico sobre el tema. 